\title{
SECONDARY SCHOOL AND UNIVERSITY RESULTS AS PREDICTORS OF SUCCESS
} IN LAW

\author{
PATRICK PARKINSON,* KAREN TREMAYNE** \\ \& JULIE STUBBS*
}

\section{INTRODUCTION}

Selection of students for university places has become an important public issue. Generally, issues of access and equity in admission to higher education have been high on the agenda of the federal government in the 1980s, and continue to be so. They have been the subject of numerous reports. ${ }^{1}$ Most of the attention has been focused upon finding alternatives to traditional routes to matriculation, as well as raising awareness among high school students of the possibilities of tertiary education. Schemes have been developed to allow applicants without traditional HSC or equivalent qualifications to gain admission to university. Thus programmes have been developed for mature-age students, aboriginals and others without traditional qualifications to take bridging courses to enable them to cope with tertiary study more successfully. ${ }^{2}$ Programmes have been developed to allow secondary schools to develop less academically rigorous courses than the HSC to enable students to study practical subjects while keeping open the possibility of tertiary study. ${ }^{3}$ Universities have accepted these qualifications where appropriate as a basis for matriculation but not as equivalent to the HSC for admission to high demand faculties.

Important as this work is, it addresses a different issue to that faced by high-demand faculties such as Law. The problem is not so much how to develop alternative minimum standards for 
matriculation and to encourage wider consideration of tertiary education in the community. The problem which we face is how to select from among the large number of suitably qualified candidates those who should be offered admission to Law. This issue has been addressed much less by the literature in recent years. ${ }^{4}$ In a higher demand faculty such as Law, a key issue which has to be addressed is whether the criteria which are adopted for admission are the fairest means of achieving the goals for which they are designed. Those goals should not be taken for granted. At present, in Australian law schools, the main criterion for selection is academic merit according to the results achieved either in the HSC or its equivalent, or tertiary performance. It is not obvious that this should be the basis for selection. Given that the majority of applicants to law schools could, if suitably motivated, succeed in passing a Law course, and that academic ability at Law is only one aspect of what makes a good professional lawyer, selection might be based on other criteria, such as aptitude and motivation for legal practice, ${ }^{5}$ or even by ballot from among a qualified group of applicants. ${ }^{6}$ Law schools could also consciously endeavour to address social, economic and racial inequalities through selection procedures. $^{7}$

It is important however to distinguish between the mainstream methods of entry and alternative methods which might apply to disadvantaged groups or for other reasons. The choice of academic merit as the criterion for mainstream admissions does not preclude having other criteria for entry, or supplementing it by interviews or other aptitude tests. On the other hand, there are important limitations on the capacity of law schools in devising admissions policy. The University of Sydney, for example, attracts a very large number of applications. Taking only first preferences into account, 1900 applications were made for Combined Law or Graduate Law in $1991 .{ }^{8}$ With this volume of applications, the Faculty must have objective and easily applicable criteria which at least reduce significantly the potential pool for selection. While random ballots or queues would be objective means of selection which are not labour intensive, it seems to be fundamental to the work of a university that academic ability should be a basis for selection, even if it is only used to reduce the pool from which the candidates are ultimately selected. It is also a basis for selection which is 
widely accepted in the community.

In general, the debate on admissions policy has not been on whether academic criteria should be used, but whether the scores which are used validly and fairly reflect academic merit. In this context, there is considerable debate about the HSC. One possible alternative is post-first year entry to law.

\section{THE HSC AS A TEST OF ACADEMIC MERIT}

The general evidence. The HSC in NSW, and its equivalents in other States, have attracted considerable attention and been subjected to a significant degree of criticism. Research on the liability of the HSC in NSW as a predictor of success in tertiary study is sparse. However, studies in Victoria ${ }^{9}$ and South Australia ${ }^{10}$ show that the HSC in those states has a correlation with first year tertiary results around the 0.5 mark, although naturally this varies from course to course and institution to institution. Correlations are higher in courses where the university work is a continuation of subjects studied at school, and lower in new disciplines.

Bias in the HSC. Some studies have appeared to indicate biases in the HSC, and its equivalents in other States. These biases appear to disadvantage students from state schools and women. Two studies in Victoria, one at the University of Melbourne ${ }^{11}$ and one at Monash, ${ }^{12}$ have shown that students from state schools tend to perform in first year at the same level as private school students with substantially higher HSC scores. The Monash study showed that students from government schools perform as well in first year as those from independent schools who have an HSC score of the order of 10-25 marks higher. However, there was no evidence of bias with respect to the father's occupational status or student's country of birth. By contrast, a study in South Australia has shown a gender bias against females but no bias in terms of the type of school attended. ${ }^{13}$ Evidence of gender bias has also appeared in the ACT where school-based assessments are moderated by the Australian Scholastic Aptitude Test ASAT). ${ }^{14}$

A major study of the reliability of the ASAT has suggested that these signs of school and gender "bias" are in fact symptoms of a different problem: the validity of having one score as representing some form of "general academic ability". ${ }^{15}$ They are not the only form of systemic bias revealed by the data. Masters and Beswick 
showed that the reason for the gender bias could be traced to the attempt to bring together different variables to record a single number on a common scale. ${ }^{16}$ In the ASAT, females did better than males in the verbal aspects of the test while males did better than females in the quantitative items. More precisely, among the verbal items, those which required literary criticism or careful reading of prose appeared to favour female students more than verbal items requiring simple recapitulation, while among the quantitative questions, the tendency was for items involving numbers to favour male students more than items involving diagrams or graphs. ${ }^{17}$ In the ACT, the consequence of the use of the ASAT as a moderator of school assessments was that males outscored females in mixedsex colleges, but females outscored males in single-sex colleges. While there was no gender bias overall, females from mixed-sex colleges were disadvantaged.

The notion of a general "ability". Making adjustments for gender would not deal with the more fundamental problem that biases of many kinds will appear in such scores if the attempts to scale and produce a single numeric score are based on invalid premises. The premise that there is such a thing as a general academic ability or that one can standardise marks across the candidature in an attempt to compensate for differences in the ability of the different cohorts in each subject, is open to serious question. For an HSC score to be valid as a measure of academic ability, it should represent a level of academic ability which does not depend on the particular courses which go together to produce that score. This in turn depends on whether all scores can be interpreted as measures of the same "ability". Two sets of scores can be brought to a common scale only if they can be usefully interpreted as representing locations on the same variable. If it cannot be said that a score in English is dealing with the same latent ability as a score in Physics, then the attempt to summate a candidate's secondary school performance in one HSC score is invalid. Masters and Beswick conclude:

All Year 12 scaling procedures are based on the assumption that scores on conceptually different courses can be interpreted as measures of the same latent ability and that it is thus appropriate to combine these scores to summarize a student's secondary school achievement in a single number. This is at best a dubious assumption. ${ }^{18}$ 
It is not necessary to form any concluded opinion on this debate, but only to note that the view has often been expressed by commentators that the idea of a single HSC score is educationally problematic and that it would be more appropriate to offer a number of scores which reflect different types of ability. This is reinforced by the fact that the significance of the HSC score for tertiary institutions is not as a measure of secondary school success but as a predictor of tertiary success. Arguably, universities should use as a criteria for selection those aspects of secondary school (or other) education which are of most relevance to the course which has been applied for.

The HSC and selection for law school. Law schools have difficulty in using particular subjects within the HSC as a predictor of success in legal study. Law, at least in the way it is studied at university, ${ }^{19}$ is a new discipline for tertiary students and it is accepted wisdom in Law Schools around the world that no one subject is a necessary prerequisite to legal education, nor is one subject a particularly good predictor. ${ }^{20}$ Thus, whatever the merits for other faculties in moving away from reliance on magic numbers which are meant to summate the intellectual ability of applicants, the law schools would find difficulty in basing admission upon performance in particular HSC subjects. At the same time, scepticism about the value of scaling according to performance on a common exam to take account of the varying abilities of a candidature, has implications for selection based upon tertiary performance as well. If there is no such thing as a general academic ability, it may be that attempts to scale results between Arts, Economics and Science students - to name only three faculties is doomed to failure. Arguably, selection ought to be based upon outstanding performance in a candidate's chosen discipline, without attempting to compare the performances of candidates in different disciplines to take account of the varying abilities of a faculty's candidature.

Comparing the HSC with interstate equivalents. A further difficulty with the HSC is that the law schools do not necessarily select candidates with qualifications only from their own State or Territory. There are methods for estimating equivalent scores for results achieved in year 12 assessments from different States, but it should not be assumed that they are comparing like with like. The 
best that can be done is for the rank order of the candidate within his or her own cohort to be compared with the rank order in the State where the university is located.

If however, the various States differ in the way they devise that rank order then comparisons are only partially meaningful. It is the case that there are significant differences between States in the way in which students' results are calculated for the purposes of matriculation. ${ }^{21}$ NSW still relies significantly on external examination. In certain other States/Territories, school-based assessments dominate as moderated by an external test such as ASAT. These divergences have increased in the last few years as a direct consequence of the policy of seeking to increase school retention rates. This has indeed been successful, and has led to demands to change the school curriculum so that it can achieve a greater diversity of goals than mere preparation for tertiary education. The less academically inclined students who stay on at school must be offered more practically- based subjects to study. The States have responded in different ways to the need to allow students to take less academic courses in the HSC year. NSW remains amongst the most conservative. ${ }^{22}$ Recently, the universities in NSW have changed their policy so that only 8 out of the 10 units presented as part of the Tertiary Entry Score need be from subjects classed as "academic" and assessed through external examination.

The decision by the government in Victoria to change its secondary school curriculum and to introduce a new VCE caused some alarm in the universities, since it reduced the validity of the leaving examination as a basis for tertiary selection. ${ }^{23}$ It is nonetheless a sign of the times, and is a consequence of allowing secondary schooling to be a phase of schooling in its own right and not merely a preparation for tertiary entrance. ${ }^{24}$ If these trends continue, it will be more difficult to assume an equivalence of school leaving qualifications between the States and Territories.

\section{Implications for Admissions Policy}

The implications of the questions concerning the HSC for admissions policy at law schools are not necessarily the same as for other faculties. For faculties which of necessity must draw their students primarily from school leavers, the HSC in its present form or with some modifications, is likely to remain the mainstream 
method of admission. Law, like Medicine and perhaps other professional faculties, is not necessarily in this position. Adelaide switched to a post-first year entry system in 1987, partially on the basis of evidence that this would provide a better basis for prediction of academic success in law. ${ }^{25}$

In the light of this, it is appropriate to consider whether selection on the basis of HSC score, however convenient it may be administratively, provides the most equitable method of selection on the basis of academic merit, if by this is meant that the HSC is being used as a measure to predict academic success in law.

\section{THE PURPOSE AND METHODOLOGY OF THE STUDY}

It was in the light of the above concerns with the HSC, and a specific proposal to move to post-first year entry ${ }^{26}$ that the predictive capacity of the HSC was analysed. The statistical study was designed to test the correlation between students' HSC performance and their success in studying law, and to compare this with the correlation between first year results and performance in law subjects. The aim of the study was to determine whether the use of unscaled university results, with or without including one introductory law subject, would provide a better basis for prediction, and therefore of selection, than the use of HSC results. The HSC was compared with unscaled results of students because it was thought neither desirable nor feasible that the Law Faculty should adopt a scaling system for the results of students in other faculties.

The question of whether the HSC, or tertiary results, is a better predictor of academic success in law is of course, only one question of many which is relevant to admissions policy. The study aimed to test one hypothesis advanced for a system of post-first year entry. A ran of other issues were addressed by Alex Ziegert's study. ${ }^{27}$

\section{The Research Cohort}

We examined the student records of 1101 students who took their first law subject at the University of Sydney either in 1983 or 1984. This was the entire entry cohort for each of these years. The years 1983 and 1984 were chosen for two reasons. First, students who enrolled in the combined degree programme (Combined Law) 
in 1984 could be expected to have completed the degree by 1990 in the normal course of events, even allowing for an honours year. Second, this was a period when the curriculum of the Faculty of Law was stable. In 1988, major changes were introduced to the Law curriculum. This would not have affected those who graduated in 1988 (five years after 1984 entry) and would have had a limited effect upon those who graduated in 1989. Thus the population of students first entering Law in 1983 or 1984 provided a large group of students, most of whom had graduated or withdrawn, and who went through the law school essentially pursuing the same curriculum. The degree structure, and the various mainstream entry categories, are described below.

Of the 1101 students, 98 students dropped out without completing any first year law course. The remainder recorded a result in one law subject or more.

Almost $32 \%$ of the students in the cohort (352), were not enrolled in a Law degree. These were students who chose to take up to four law subjects as part of their Arts, Economics or Science degree. This was permitted at the University of Sydney during this period, and there were no restrictions on the enrolment of students from these faculties in the first four courses of the law degree which were taught on the main university campus. The availability of this group of non-law students who took some law subjects allowed us to study the performance of a sizeable number of students within a broad band of HSC performance. Taking the entire cohort studied, the lowest HSC score recorded was 271, the highest was 490 .

While some of the non-law group of students attempted only one law subject (Legal Institutions) others attempted up to four subjects. In total, 55 of these students later went on to gain a place in the Law degree with advanced standing either as a graduate entrant or on the basis of outstanding performance in the first or second year of tertiary study, and completed a law degree.

The study was therefore able to examine the performance of students in law subjects beyond the narrow range of those who gained admission to Combined Law as a result of a high HSC score. This was an important feature of the study. An examination of the correlation between the HSC score and average performance for only those students who had been admitted into Combined Law 
from the HSC would have given us a relatively narrow band of HSC scores on which to base correlations. Furthermore, we would not have been able to compare the performance of these students in the first year of the combined programme with students who might have applied to study Law, but were not admitted. The availability of such a large contingent of students who had results in law subjects and who did not gain entry to Law allowed us to test the reliability of the HSC and first year results respectively over a very broad range of HSC scores. ${ }^{28}$

\section{Statistical Methods}

The data was acquired from the student records held on the university's computer. A special programme was written to extract data for each student. Only the student identification number was used, and the gender of each student was also recorded. A variety of statistical techniques were used to analyse the data. These included measures such as arithmetic means, medians and standard deviations. They were calculated in order to describe some of the main features of the underlying distributions from which the data were taken. In addition, analyses involving two or more variables were undertaken with a view to establishing relationships.

Since a particular focus of the research was to compare HSC scores with first year tertiary results as predictors of success in legal studies, correlation coefficients were calculated to examine the strength of the relationship, if any, between performance in law studies and each of the independent variables - HSC score and first year tertiary results. The value of the correlation coefficient indicates the strength of linear association between two variables. It can range in value between $+\mathrm{l}$ and -1 with the sign on the coefficient indicating whether the relationship is a positive or negative one. A positive correlation is one in which a high score on one measure is associated with a high score on another measure, whilst a negative correlation indicates that a low score on one measure is associated with a high score in the other measure. The size of the correlation indicates how close pairs of observations would tend to cluster around a straight line. The closer the coefficient is to $\mathrm{l}$ or -1 , the greater the positive or negative correlation. The closer it is to 0 , the weaker the correlation. The pvalue indicates how significant the correlation coefficient is. When 
testing at the $5 \%$ (1\%) significance level, the p-value is compared to a value of $0.05(0.01)$. The $\mathrm{p}$-value represents the probability that the correlation is simply due to chance rather than any real relationship between the variables. It is conventional in statistical analysis to accept as statistically significant any result which has a probability of arising through chance of less than five percent. If it is smaller than this the correlation coefficient is said to be significant. Thus a p-value of 0 shows the correlation is significant at all conventional levels. Where the p-value was zero, the tables simply record the results as "significant". Where the $p$ value was not zero, the tables provide the actual $p$ value.

Further, average performance in all law subjects, HSC score and results in Legal Institutions were recoded into quartiles and cross-tabulations were considered. Quartiles divide a distribution into four, in that $25 \%$ of students achieve a mark of quartile 1 (q1) or less, $50 \%$ obtain a mark of q2 or less and $75 \%$ achieve a mark of q3 or less. Also, simple and multiple regressions were carried out with average performance in law studies being considered as the dependent variable. Explanatory variables used were HSC score, first year non-law results, and first year results including Legal Institutions.

Other specific methods and statistical measures are explained in the course of this paper where the relevant results are given.

\section{Entry Categories}

The cohort was sorted by reference to entry categories as follows:

l Entry into Combined Law straight from HSC. The Faculty of Law had then (and has now) three combined degree programmes. Students may enrol concurrently with Law in the Faculty of Arts, Economics or Science. Normally, the degree takes five years. Under the pre-1988 curriculum, students took four subjects in the first three years of the Combined Degree programme. These were Legal Institutions, Public Law, Contracts and Torts. These formed part of both the Law degree result, and the result for the other degree taken. Now students take six law courses in the first three years. The first degree is normally completed after three years, and in the last two years of the degree programme, 
students study law exclusively. The majority of students enter Law through the Combined Degree programme on the basis of rank order of applicants. Students were, at the time of these entry cohorts, ranked according to a numerical figure ascribed to performance in the HSC. In each year there is a cut-off which indicates the HSC score below which a place in Law could not be secured. This figure is set only on the basis of demand. There is no pre-set cut-off point above the matriculation score for the university. In 1983, that cut-off score was 407. In 1984, it was 406.

2 Entry into Combined Law with previous tertiary record. A limited number of students were permitted to transfer into Law on the basis of excellent performance in first year (or occasionally later). The first year results were moderated by HSC performance to create a rank order of applicants. Most such applicants were from within the University of Sydney.

3 Enrolment in Legal Institutions, Contracts, Torts, or Public Law by students not enrolled in a Law degree. As explained above, these were students who chose to take one or more law subjects for their other degree. As for the Law students, satisfactory performance in Legal Institutions was a prerequisite to the study of the other law subjects.

4 Entry direct into Law straight from HSC. At the time of this study, a limited number of students enrolled on the basis of HSC performance in a four year law degree, known colloquially as "straight law". In practice, these students tended to have lower HSC scores than the Combined Law entrants. The Combined Law degree was regarded as the more desirable of the two. The lowest HSC score in this group was 385, the highest was 451 . The four year degree has since been abolished.

5 Entry into Law with previous tertiary record, but without a completed degree. These students enrolled in the four year "straight law" programme following a certain period of tertiary study which had not led at that stage to the award of a degree. Tertiary performance was the criterion for selection in the same way as for category two in the Combined Law programme. There were only six students in this category.

6 Entry into Law as graduate. About 60-70 students per year 
entered law as graduates in another discipline. Graduate Law is a three year degree programme.

The initial sorting was done by computer, but extensive checks on the data were conducted by the researchers to ensure the accuracy of the data and the categorisation. In all, about one quarter of all the student records used in the study were checked in this way. In the course of this, three further categories were created:

7 Students with first degrees who enrolled in Combined Law rather than the more usual three year law degree (Category 6).

8 Students who enrolled in Combined Law with interstate HSC qualifications.

9 Students who initially enrolled in "straight” law (Category 4) but then transferred to the Combined Law programme.

The entry category selected for each student was that category in which the student first enrolled in a law subject. Students who first enrolled in Legal Institutions in 1983 or 1984 as a non-law student, and then subsequently transferred into Law, were treated as category three students. The category three students who went on to gain law degrees are considered separately later in the paper.

The numbers in each category were as follows:

Table 1: Numbers of Students by Entry Category

\begin{tabular}{|c|c|}
\hline Entry Category & Number of Students \\
\hline 1 & 422 \\
2 & 90 \\
3 & 352 \\
4 & 82 \\
5 & 6 \\
6 & 131 \\
7 & 2 \\
8 & 2 \\
9 & 14 \\
\hline Total & 1101 \\
\hline
\end{tabular}

Table 2 indicates the numbers in each subject of those in 
category three who were not enroled in Law, who had an HSC score recorded and who took one or more law subjects with a result being recorded. 
Table 2: Non-law Students by Subject

\begin{tabular}{|c|c|}
\hline Subject & Number of Students \\
\hline Legal Inst & 278 \\
Contracts & 153 \\
Torts & 133 \\
Public Law & 176 \\
\hline
\end{tabular}

\section{Results and Discontinuations by Entry Category}

Table 3 gives the numbers in each entry category of those students with one or more results in $\mathrm{Law}^{29}$ and shows for each category, the distribution of mean and median results. As categories five, seven, eight and nine have so few students within them, details of these students are combined in the tables. The "result" in this table refers to the overall result of each student, averaged from all the law subjects taken, including supplementary examinations. Thus if a student only took Legal Institutions, then his or her score would be the score achieved in that one subject. ${ }^{30}$ Of the six main entry categories, the first (entry on the basis of HSC score into Combined Law) showed the best overall mean and median scores Not surprisingly category three, those students enrolled in other degrees who chose to take individual law subjects, fared least well. Of all the entry categories for the LLB, the performance of the graduate intake was the lowest.

Table 3: Distribution of Mean and Median Results by Entry Category

\begin{tabular}{|c|c|c|c|c|}
\hline Category & Number & Mean & Median & $\begin{array}{c}\text { Standard } \\
\text { Deviation }\end{array}$ \\
\hline 1 & 392 & 64.4 & 66 & 7.6 \\
2 & 82 & 63.9 & 65 & 6.3 \\
3 & 330 & 53.5 & 54 & 9.7 \\
4 & 69 & 60.1 & 61 & 7.0 \\
$5,7,8,9$ & 22 & 617 & 615 & 75 \\
6 & 108 & 59.1 & 60 & 8.9 \\
\hline
\end{tabular}


Table 4 indicates the number of students, by reference to entry category, who withdrew from Law, or in the case of categories 1-3, from Legal Institutions, without reaching a point where a numerical result was recoded.

Table 4: Withdrawals from Law Without Completing a 1st Year Course

\begin{tabular}{|c|c|c|c|}
\hline Category & Total Students & $\begin{array}{c}\text { Number of } \\
\text { Withdrawals }\end{array}$ & \% of Total \\
\hline 1 & 422 & 30 & 7 \\
2 & 90 & 8 & 9 \\
3 & 352 & 22 & 6 \\
4 & 82 & 13 & 16 \\
$5,7,8,9$ & 24 & 2 & 8 \\
6 & 131 & 23 & 18 \\
\hline TOTAL & & 98 & \\
\hline
\end{tabular}

Students who entered law school directly from the HSC and undertook a "straight law" degree, and those who entered law school as graduates had the highest withdrawal rates.

Table 5 compares the performance of females and males. There is no significant difference in the performance of male and female students.

Table 5: Distribution of Results for Females and Males

\begin{tabular}{|l|c|c|c|c|}
\hline & Number & Mean & Median & $\begin{array}{c}\text { Standard } \\
\text { Deviation }\end{array}$ \\
\hline Females & 459 & 60.37 & 61 & 9.14 \\
Males & 544 & 59.51 & 60 & 10.05 \\
\hline
\end{tabular}

\section{RESULTS OF THE ANALYSIS ON PREDICTION OF SUCCESS IN LAW}

The correlation coefficient between HSC scores and the mean 
performance in all law subjects attempted, was calculated. Table 6 indicates the correlations between HSC and mean performance for all students except those in categories three (non-law) and six (graduate entry), first in relation to all law students, and then including only those who graduated with a law degree. The exclusion in this table of categories three and six means that the group consists only of students with a recent HSC score who were admitted to the Law degree on the basis of the HSC or shortly afterwards. $^{31}$

Table 6: Correlation Between HSC Score and Mean

Performance (all students except categories 3 and 6)

\begin{tabular}{|l|c|c|}
\hline & All Students & Law Graduates Only \\
\hline Number of Students & 500 & 340 \\
Correlation coefficient (r) & 0.261 & 0.351 \\
\hline
\end{tabular}

Results significant

The correlation is somewhat higher in the category of those who went on to complete law degrees than when all the law students are taken into account. The correlations do vary somewhat when analysed by entry category as Table 7 shows. Table 7 gives separate correlations for entry categories one, two and four. These were the three main categories of entry other than Graduate Law, namely entry to Combined Law on the basis of the HSC, entry to Combined Law by transfer, and entry into "straight” Law by HSC score.

Table 7: Correlation Between HSC Score and Mean Performance by Entry Category

\begin{tabular}{|c|c|c|c|}
\hline $\begin{array}{c}\text { Entry } \\
\text { Category }\end{array}$ & $\begin{array}{c}\text { Correlation } \\
\text { Coefficient }\end{array}$ & $\begin{array}{c}\text { Number of } \\
\text { Students }\end{array}$ & Significance \\
\hline 1 & 0.2740 & 366 & 0 \\
2 & 0.3930 & 59 & .0021 \\
3 & 0.0996 & 60 & .45 \\
\hline
\end{tabular}

The correlation in categories one and two is significant; in category four (those students who came into "straight" law from 
the HSC) it is not significant.

The above tables examine the correlation between the HSC and mean performance in law subjects overall when only Law students are considered. This involved a relatively narrow band of HSC score. Table 8 depicts the correlation between the HSC and mean overall performance, when all students are considered, whether enrolled in Law or not, and even if their mean overall performance is in only one subject, Legal Institutions. The figure for those who graduated with a Law degree in this table includes those who began in category three. That is, they began as non-law students and eventually enrolled in Law either by transfer or by graduate entry.

Table 8: Correlation Between HSC and Mean Overall Performance (all categories except 6)

\begin{tabular}{|l|c|c|}
\hline & All Students & $\begin{array}{c}\text { Law Graduates } \\
\text { only }\end{array}$ \\
\hline Number of students & 780 & 380 \\
Correlation coefficient (r) & 0.568 & 0.341 \\
\hline
\end{tabular}

Results significant

The results suggest a fairly weak linear relationship between the two variables if only the narrow band of students admitted to the law degree are included (Table 6) but a strongest correlation results if the non-law students are included, since this gives a broader spectrum of HSC performances (Table 8).

Table 9 gives the correlation between the HSC score and performance in individual subjects for all students except graduate entry (Category 6), both in total and divided into law students and non-law students (Category 3). The total provides an assessment of the correlation in each subject across the range of HSC scores. ${ }^{32}$ For law students, the correlation is generally lower than for nonlaw students in the Law I subjects. 
Table 9: Correlation Between HSC and Performance in Law I

\begin{tabular}{|l|c|l|c|c|l|l|}
\hline Subject & \multicolumn{2}{|c|}{ Law Students } & \multicolumn{2}{c|}{$\begin{array}{r}\text { Non-law } \\
\text { Students }\end{array}$} & \multicolumn{2}{c|}{ Total } \\
& \multicolumn{2}{|c|}{$\mathrm{r}$} & $\mathrm{n}$ & $\mathrm{r}$ & $\mathrm{n}$ & \multicolumn{2}{c|}{$\mathrm{r}$} & $\mathrm{n}$ \\
\hline Legal Inst & 0.158 & 500 & 0.3688 & 278 & 0.509 & 778 \\
Contracts & 0.206 & 447 & 0.3803 & 153 & 0.382 & 600 \\
Torts & 0.339 & 444 & 0.2071 & 133 & 0.334 & 577 \\
Public Law & 0.200 & 466 & 0.2244 & 176 & 0.369 & 642 \\
\hline
\end{tabular}

Results significant

Table 10 shows that the correlations for law students are higher in Law II and Law III, and for the small numbers who did a fourth year of Law (Category 41, than they were for first year subjects with the exception of Torts.

Table 10: Correlation Between HSC and Performance in Later Years

(all students except categories 3 and 6)

\begin{tabular}{|l|c|c|}
\hline Subject & \multicolumn{2}{|c|}{ Law Students } \\
& r & n \\
\hline Law II & 0.326 & 384 \\
Law III & 0.360 & 358 \\
Law IV & 0.314 & 54 \\
\hline
\end{tabular}

Results significant

As noted above, 55 students who first look law subjects within category three, went on to enrol in the Law degree. Of these, 40 had an HSC score recorded.

Table 11: Performance of Law Graduates from Category 3

\begin{tabular}{|l|c|c|}
\hline Performance & HSC & Final \\
\hline Number & 40 & 55
\end{tabular}


Correlation between HSC and final performance 0.15.

These results may be compared with the mean performance of the other entry categories, (Table 3) and demonstrates the very competent performance of this group. The mean performance is in fact higher than for any other Category. Two students were found in this group with EEC scores below 300, and who successfully completed law degrees. The correlation between HSC result and final performance for this group was, not surprisingly, very low.

\section{Crosstabulations}

The predictive power of the FIX for law study can also be tested by dividing the cohort into quartiles based upon performance in the HSC, and crosstabulating this with quartiles for mean law performance. Table 12 considers the relationship between HSC score and mean performance using a crosstabulation.

Table 12: Crosstabulation: HSC Score and Mean

Performance

(all students except categories 3 and 6)

\begin{tabular}{|c|c|c|c|c|c|}
\hline $\begin{array}{c}\text { HSC } \\
\text { Score } \\
\text { Quartile }\end{array}$ & \multicolumn{4}{|c|}{ Mean Result Quartile } & Total \\
\hline 1 & $\mathbf{1}$ & $\mathbf{2}$ & $\mathbf{3}$ & $\mathbf{4}$ & \\
2 & 36 & 40 & 35 & 25 & 135 \\
3 & 27 & 30 & 38 & 34 & 129 \\
4 & 12 & 26 & 37 & 56 & 131 \\
Total & $\mathbf{1 0 4}$ & $\mathbf{1 3 0}$ & $\mathbf{1 3 6}$ & $\mathbf{1 3 0}$ & $\mathbf{5 0 0}$ \\
\hline
\end{tabular}

Chi-squared $=40.66$

Results significant

The chi-squared statistic is calculated and used for testing the null hypothesis of no association between the variables in a two way table. In this table, the value of chi-squared is significant when testing the null hypothesis of no association between the variables. The table indicates a pattern which supports the idea that a student 
entering the Law Faculty in a certain HSC quartile is very likely to appear in the same or adjacent quartile when final performance is considered. That is, a student entering in the first quartile with regard to HSC score will most probably achieve a final result in the first or second quartile of the range. Conversely, a student entering in the first quartile of HSC scores is not likely to graduate with results in the third or fourth quartile. Those entering with good HSC scores do well on the whole, whilst those with the poorest HSC scores amongst the candidates admitted tend to remain towards the bottom of the pack.

The correlation between the HSC score and law students' results in first year subjects other than Legal Institutions was also calculated.

Table 13: Correlation Between HSC and 1st Year Results

\begin{tabular}{|l|c|c|}
\hline & All Students & Law Graduates only \\
\hline Number of students & 780 & 380 \\
Correlation coefficient & 0.568 & 0.341 \\
\hline
\end{tabular}

Results significant

These results for the law students suggests that the HSC correlates better with non-law results than it does with performance in law subjects. This is subject to the qualification that comparisons between correlations are problematic unless the same group of students is used. ${ }^{33}$ The law students represent a group of students with a limited range of HSC scores, and therefore this result should not be generalised to university courses in other faculties.

\section{DISCUSSION OF THE PREDICTIVE VALUE OF THE HSC}

The above results confirm that the HSC does have some predictive value for success in legal studies, but this predictive power is not particularly great. Beswick et a1 suggest two reasons why this may be so. ${ }^{34}$ First, the predictive power of any examination is likely to decline the further away from it one goes. The Combined Law degree lasts a minimum of five years, two years longer than most of the other degrees. Second, as has been noted, Law is a new discipline to almost all students, and thus there 
is no subject included in the HSC score which is of particular predictive value. Not surprisingly, the best predictor of success in science at university is a science result in the HSC. ${ }^{35}$ Inevitably, the HSC is likely to be less reliable as a predictor of success in disciplines such as Law and Medicine than in university courses which build on knowledge acquired in the later years of school.

Both hypotheses are supported by the research reported here. When all students including the non-law students, are included, the correlation is highest with Legal Institutions, and declines for those subjects taken subsequently (Table 9). The Law students show a different pattern; correlations for Law II and Law III are higher than for Law I (Tables 9 and 10). However, this may perhaps be explained by the patterns of work effort of the Combined Law student body. There is a tendency for students to give primary effort to the other degree in the first three years of the combined programme for this is the major focus of their study at that stage. Law, in the first three years, is only a subsidiary discipline for them. This changes once the other degree is completed. In Law II and Law III students are engaged only in the study of Law.

The second hypothesis is also borne out. Correlations with the HSC are higher for the non-law subjects than for Law. The HSC is a better predictor of success in first year non-law subjects than it is for Legal Institutions. Furthermore, as will be seen, the best predictor of success in Law is success in Law.

It will be noted that the correlations improve when only those students who gained law degrees are considered. The HSC is thus a better predictor of the results of those who complete the law degree than it is of all students admitted to the course. It may be that this correlation for graduates only is a more reliable indicator of the HSCs predictive capacity for success in law. Given the high quality of the law intake, failures and withdrawals from the course are best explained as withdrawals of those who drop out for non-academic reasons such as health or financial pressures, or who find themselves unsuited to legal studies, or otherwise choose another career path, rather than those who are academically incapable of passing. Those who graduate in law are those who choose to, or are able to persist with law studies. 


\section{Four Unit Maths and the HSC}

There has been concern within the University of Sydney that the inclusion of four unit maths in the scaled New South Wales HSC score may have a distorting effect on the reliability of the HSC result, that is, students who take four unit maths in the HSC achieve an HSC score higher than is justified by reference to their performance in university. It is clearly the perception that four unit maths does give to candidates a significant advantage, and more and more students are taking it. In 1984, the proportion of first year medical students at the University of Sydney who had taken the subject at the I-ISC was 53\%. In 1989 it was 88\%. Overall, about seven percent of the candidature were enrolled in four unit maths in 1989 (3642 out of 50655) compared to five percent in 1985. A similar increase is to be found among law students. $15.3 \%$ of final year students in 1990 had taken four unit maths, compared to $47.4 \%$ of first years. ${ }^{36}$ It is difficult to prove that the scaling of four unit maths does distort the order of merit in the HSC. It is argued that these students benefit from a double scaling. They sit a common paper with the three unit candidates, and the four unit additional paper is then scaled in the same way as scaling occurs between two and three unit subjects. However, the three unit results (on the common paper) have already been scaled to account for the difference in standard between two and three unit candidates. Thus the four unit candidates get a mark on the common paper which is scaled up to account for the difference between two units and three units, and their additional paper is scaled up to account for the difference between three units and four units.

The result of this is that the mean mark for four unit maths is exceptionally high. In 1988, the mean mark was 44.56 and the median mark was 45.3 (out of 501, 97.37\% of the candidature received a final scaled mark of $70 \%$ or above, and $53 \%$ had a scaled mark of $90 \%$ and above. ${ }^{37}$ With cut-offs as high as those for Medicine and Law, quite possibly taking four unit maths could be the difference between success and failure in getting into the chosen course.

A further concern has been that the effect of a distortion caused by four unit maths has a disproportionate impact on certain sectors of the population. Women in particular may be discriminated against because at present, nearly two-thirds of the candidates are 
men (1988 figures — 2234 male, 1140 female). Furthermore, not every school teaches four unit maths. This may adversely affect state school students in the country, and in certain urban areas.

The results are given in Table 14. 88 students in the cohort had a score in four unit maths. The mean score was 177, median 179, standard deviation 10.7 . Of these, $64^{38}$ were in category 1 . This group was compared with the category 1 students who did not take four unit maths. Those students who did take four unit maths achieved higher HSC scores than those who did not. Conversely, the group which did not take four unit maths performed better in Law than the group that did take it, but the difference between the two groups was not statistically significant.

Table 14: Four Unit Maths in HSC and Mean and Median Results in Law (category 1 only)

\begin{tabular}{|c|c|c|c|c|}
\hline $\begin{array}{c}\text { 4-unit } \\
\text { maths }\end{array}$ & Number & Mean & $\begin{array}{c}\text { Standard } \\
\text { Deviation }\end{array}$ & Median \\
\hline $\begin{array}{c}\text { HSC Score } \\
\text { Yes }\end{array}$ & 64 & 434.8 & 19.9 & 432 \\
No & 326 & 427.5 & 18.7 & 423 \\
Law Results & & & & \\
Yes & 64 & 64.1 & 7.7 & 64 \\
No & 326 & 64.7 & 7.6 & 66 \\
\hline
\end{tabular}

\section{Predictive Value of First Year Non-Law Results}

The students' performance in first year, excluding Legal Institutions, was correlated with final performance to test whether selection based upon a first year which included no law subjects would provide a more reliable basis for selection than the HSC. Table 15 shows the correlation between the average grade in first year non-law subjects and final performance for all Law students in the Combined Law degree or who transferred into "straight" Law with a previous tertiary record (Category 5).

Table 15: Correlation Between 1st Year Non-law and Mean

Performance (all students except categories 3 and 6)

\begin{tabular}{|l|l|l|}
\hline Number of Students & All Students & Law Graduates only \\
\hline
\end{tabular}




\begin{tabular}{|l|c|c|}
\hline Number of students & 780 & 380 \\
Correlation coefficient (r) & 0.568 & 0.341 \\
\hline
\end{tabular}

Result significant

The correlation between these first year results and average law performance should be compared with Table $6 .^{39}$ The correlation is higher than for the HSC when all students are considered (0.425 compared with 0.261) but about the same when only those who graduate with law degrees are taken into account (0.348 compared with 0.351 ). Table 16 shows the same correlation, but including the non-law students (Category 3).

Table 16: Correlation Between Non-law and Mean Overall Performance (all students except category 3)

\begin{tabular}{|c|c|c|c|}
\hline $\begin{array}{c}\text { Number of } \\
\text { Students }\end{array}$ & $\begin{array}{c}\text { All Students } \\
\mathbf{r}\end{array}$ & \multicolumn{2}{|c|}{$\begin{array}{c}\text { Law Graduates only } \\
\mathbf{n}\end{array}$} \\
\hline 723 & 0.559 & 317 & 0.355 \\
\hline
\end{tabular}

Result significant

When the correlation is calculated taking account of all students, including category three, it is quite high. However, this is not very surprising. For the category three students, the correlation is between first year non-law subjects and just Legal Institutions or up to three other law subjects. This does not give a long range prediction. In comparing Table 16 with Table 8, it is evident that the correlation is not quite as high as for the HSC (0.568). Further the high correlation is not sustained over the life of a law degree. If the hypothesis is correct that the sample of those who graduate in law excludes those whose performance is affected by non-academic factors leading to withdrawal, then it is unsafe to conclude that first year tertiary results, excluding a law subject, provides a better basis for prediction than the HSC.

\section{Predictive Value of Law Subjects}

The other variables which were used to predict law performance generally were results in individual first year law subjects. Table 17 provides the correlation between the result in each of the Law I subjects and mean performance. 
Table 17: Correlation of First Year Results with Mean

Performance

\begin{tabular}{|l|c|c|c|c|}
\hline \multirow{1}{*}{ Subject } & \multicolumn{2}{|c|}{ Law Students } & \multicolumn{2}{c|}{ Total } \\
& \multicolumn{2}{|c|}{ Mean Performance } & \multicolumn{2}{c|}{} \\
& $\mathrm{r}$ & $\mathrm{n}$ & $\mathrm{r}$ & $\mathrm{n}$ \\
\hline Legal Inst & 0.6963 & 659 & 0.555 & 458 \\
Public Law & 0.7309 & 623 & 0.673 & 462 \\
Contracts & 0.7521 & 595 & 0.686 & 456 \\
Torts & 0.7702 & 590 & 0.721 & 455 \\
\hline
\end{tabular}

Results significant

These figures for all the students however, must be read with the important qualification that the mean performance includes the subject with which that mean performance is being correlated, and that the correlations for the category of all students will be inflated by the presence of a certain number of students for whom the mean performance is based on just one or two subjects. Thus while 659 law students enrolled in Legal Institutions, only 623 went on to study Public Law and the number dropped to 590 and 595 respectively for Torts and Contracts. 528 students in the cohort completed Law 11. The more reliable figures therefore are those of graduates only where the individual subject is just one of fourteen ${ }^{40}$ subjects which make up the figure of average performance. ${ }^{41}$

\section{Predictive Value of First Year Results including Legal Institutions}

When Legal Institutions is factored in to the first year results, so that all first year subjects are included, a very high correlation results. This can be seen from Table 18, which records the performance of all Combined Law students who had a set of first year results including legal Institutions. 
Table 18: Correlation of Performance in Fifth Year Subjects, including Legal Institutions with Mean Results in All Law

Subjects Taken

\begin{tabular}{|l|c|c|}
\hline & Number & r \\
\hline All students & 414 & 0.693 \\
\hline Graduates only & 267 & 0.688 \\
\hline
\end{tabular}

Results significant

Although these results are again subject to the qualification that Legal Institutions forms a component of the mean results in Law, the correlation is not much affected by whether all law students are examined or just those who went on to graduate in law.

This result suggests that if students must be selected on the basis of first year results in another faculty which included one general law subject, then this result would be a good predictor of success in Law and a considerably better predictor than the HSC. It is unlikely that there is any particular significance to be attached to the particular Legal Institutions course at the time considered in this study. The other first year courses, Public Law, Torts and Contracts also predict well - indeed they are better predictors. However, it is inappropriate to compare Legal Institutions with other law subjects. Legal Institutions was the first studied. It cannot be said how the results might differ if Contracts, Torts or Public Law were to be studied alone before Legal Institutions.

\section{Further Analysis with a Constant Group}

The correlations given thus far, may be challenged on the basis that the group am not constant. Thus when the HSC and mean performance is calculated (excluding certain groups), those who feature are all those who have an HSC score. When non-law subjects in first year are correlated with mean performance in Law, the group consists of all those who have a set of first year non-law results. The two groups are not the same however. There are many students with a set of non-law results who do not have an HSC score, either because there is missing data or because these students were admitted on a basis other than the HSC.

The following analyses were conducted on the sample of 317 
students (excluding Categories 3 and 6) who had a complete set of final performance, HSC aggregate, Legal Institutions, average mark for first year non-law subjects, law and non-law and average mark for first year law subjects. Table 19 presents various correlations with this constant group.

Table 19: Correlation with Mean Performance

\begin{tabular}{|l|c|}
\hline \multicolumn{1}{|c|}{ Results } & Mean Performance (r) \\
\hline HSC & 0.277 \\
First year Non-law & 0.424 \\
First year Law and Non-law & 0.66 \\
\hline
\end{tabular}

The results for this constant group are consistent with those provided previously. The highest correlation with mean performance in Law is for first year tertiary results including a law subject. Further, a regression analysis of the data was conducted in an effort to consider the relationship of mean performance to certain predictor variables (Table 20). A means of assessing the importance of a variable in a model is via its $t$-value. A typical rule of thumb is that a $t$-value greater than two in absolute value indicates that the variable is a significant determinant of the dependent variable. The $t$-value for the HSC in equation 1 may be compared with that for non-law in equation 3, and for law and nonlaw in equation 4.

Table 20: Regression Analysis

\begin{tabular}{|l|ccc|}
\hline \multicolumn{1}{|c|}{$\begin{array}{c}\text { Dependent } \\
\text { Variable }\end{array}$} & \multicolumn{3}{|c|}{$\begin{array}{c}\text { Mean Performance } \\
\text { Coefficient }\end{array}$} \\
\hline EQUATION 1 & & & $\boldsymbol{p}$ value \\
Constant & 29 & 4.04 & 0 \\
HSC score & 0.09 & 5.13 & 0 \\
& rsq $=0.077$ & Durbin Watson $=1.87$ & \\
& & & \\
EQUATION 2 & & & 0 \\
Constant & 24.48 & 4.08 & 0.015 \\
HSC score & 0.04 & 2.46 &
\end{tabular}




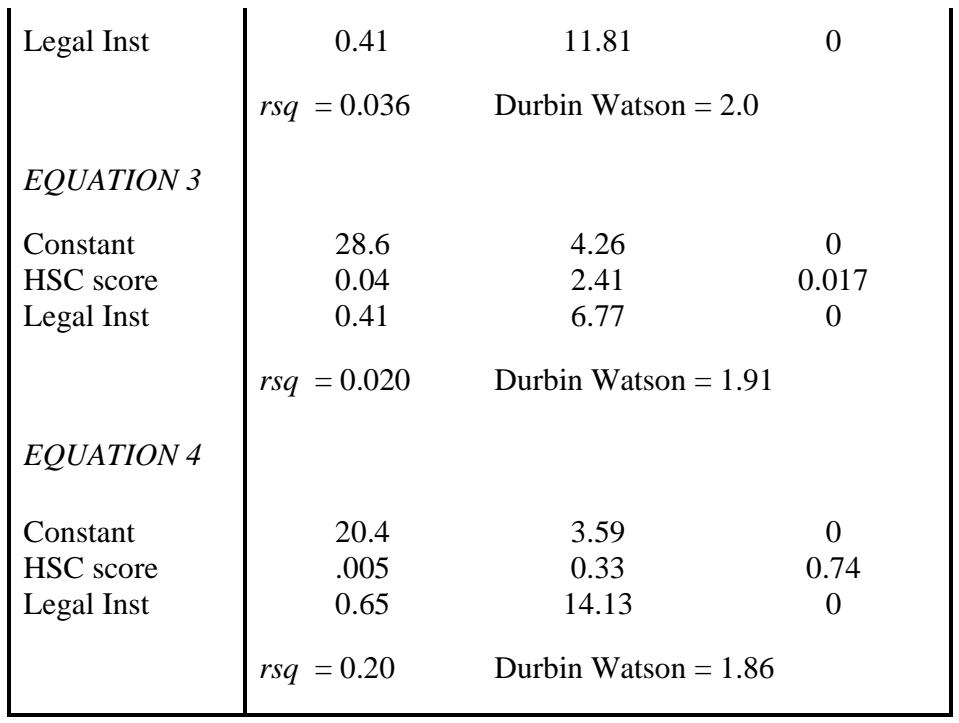

The rsq value is a measure of the explanatory power of the model. Thus Equation 3 shows that a combination of first year performance (without Legal Institutions), and the HSC explains $20 \%$ of the variation. On this basis, equation 4 (first year law and non-law results) provides the best explanatory model, since it explains $44 \%$ of the variation. This finding supports those previously presented using correlation coefficients. In the regressions, the Durbin-Watson value implies that no obvious model inadequacy is detected by this statistic. ${ }^{42}$

While as has been noted these results aw qualified by the observation that the result in Legal Institutions does form one component of average performance, this is only one subject out of 14 for the great majority of these students, since so few Combined law students withdrew after passing Legal Institutions. Law and non-law first year results thus provide the best predictor of success in the degree as a whole, and together with the HSC this explains $44 \%$ of the variance in results of the students. The $p$-value in equation 4 shows the HSC is not significant in this. 


\section{SOCIO-ECONOMIC AND GENDER IMPACT OF CHANGES \\ TO ADMISSIONS POLICY}

\section{Schools Data}

For the reasons given by Ziegert, ${ }^{43}$ law schools are unlikely to achieve a radically different social mix of students by abandoning HSC entry. The pool of applicants from which law students are drawn is itself a reasonably homogenous group.

Nonetheless, an indication was sought as to whether a shift to post-first year entry would alter the socioeconomic mix of students studying Law. Detailed socio-economic data was, unfortunately, not available. However, a limited picture emerges by considering the mix of school backgrounds from which students would be drawn using the HSC and first year results respectively as a very rough index of socioeconomic background. Where school information was available, students were given a code according to the type of school they had attended. The coding system used was:

\begin{tabular}{|llll|}
\hline 1 & Government & 2 & Catholic Systemic \\
3 & Catholic Non-Systemic & 4 & Other Independent \\
\hline
\end{tabular}

The Catholic systemic schools are those parish schools which parallel the state school system, and therefore these two categories together were deemed to represent a public education. Categories three and four are private fee-paying schools. The numbers in each category are shown in Table 21:

Table 21: Numbers In Each School Category

\begin{tabular}{|cc|}
\hline School Code & Number \\
\hline 1 & 291 \\
2 & 60 \\
3 & 145 \\
4 & 241 \\
\hline
\end{tabular}

The remainder (22) were either TAFE students or difficult to code.

Two models were evaluated using the actual results and school 
backgrounds of students in the 1983 and 1984 cohorts. In the first model, students were selected on the basis of their overall first year performance including one Law subject; in the second model, students were selected on the basis of first year performance without a law subject. The students were ranked according to results in HSC, first year Law and first year non-Law subjects. The frequency table, in each case, of the various types of schools attended was then obtained.

Table 22 shows the distribution of the different types of schools attended by the best 200 students with school codes present, based first upon entry determined by HSC score, and then with the two models described above. Based on HSC score, the majority of students selected (57.5\%) were from private fee-paying schools. In the model where selection is based on first year results including one law subject, there were approximately equal numbers of students from public schools as from fee-paying schools.

Table 22: Distribution Of Schools Attended

\begin{tabular}{|cccc|}
\hline School Type & Number & Total & \% \\
\hline HSC & & & \\
1 & 76 & & \\
2 & 9 & 85 & 42.5 \\
3 & 37 & 15 & 57.5 \\
4 & 78 & & \\
Law \& Non-law Results in First Year & & \\
1 & 89 & & 50.5 \\
2 & 12 & 101 & \\
3 & 35 & & \\
4 & 64 & 99 & \\
Non-law Results in First Year & & \\
1 & 82 & & \\
2 & 13 & 95 & \\
3 & 41 & 105 & \\
4 & 64 & &
\end{tabular}

This data only provides a very broad indication of how a change in admission policy might affect the socioeconomic mix. 
Attendance at a state or Catholic systemic school does not necessarily mean that the socioeconomic status of the parents is any lower than for those students who attended private schools. ${ }^{44}$ However, with this qualification, it may be noted that with a move to deferred entry, the mix of school backgrounds alters, and this is more marked where the top 200 students in first year, including Legal Institutions, are considered.

\section{Gender Impact}

Using a similar modelling procedure, the likely impact of selection based on the HSC and first year results upon the gender mix of the student body was considered. Selection on the basis of first year performance including Legal Institutions also made a difference in this sample to the numbers of each gender selected (see Table 23). While further study would be necessary before any conclusions could be drawn from this about gender bias in the HSC, it is noticeable that the mix is more even where selection is based upon first year law and non-law results than it is when based on HSC scores.

Table 23: Gender Mix of Top 200 Students

\begin{tabular}{|lcc|}
\hline & Number & \% \\
\hline HSC & & \\
& & \\
Male & 113 & 56.5 \\
Female & 87 & 43.5 \\
Law \& Non-Law & & \\
$\quad$ Male & 97 & 48.5 \\
Female & 103 & 51.5 \\
\hline
\end{tabular}

\section{CONCLUSIONS}

The analysis carried out suggests that there is a correlation between the HSC and performance in Law, and that HSC score is indeed a moderately good predictor when looking at students' final degree performance. However, since Law is a discipline which does not build specifically upon knowledge acquired in the HSC, 
and which is new to students, the HSC does not predict performance in Law as well as it might do for some other disciplines. While some improvement in predictive power might be achieved if students were selected only on the basis of first year performance in another degree programme, it is unsafe to conclude that unscaled results in first year subjects offer a better basis for selection on academic merit than the HSC. The analysis points quite strongly to the fact that an admissions policy which selected students on the basis of first year performance including one law subject would be a very much more reliable predictor of success in the law degree as a whole.

The relevance of academic results as predictors of success in law is only one aspect of admissions policy. Indeed, some may not regard it as an especially significant aspect. Apart from equity considerations, which are addressed in universities through alternative means of admission, other factors which are of importance include the manner in which students select law as a discipline to study, and questions about the optimal time to study law. The possibility that Australian law schools will adopt the American model of graduate schools must be considered, although this brings many other difficulties in selecting between qualified applicants. For as long as combined degree programmes exist however, and for as long as academic merit is promoted as the basis for selection, questions about the reliability of our performance indicators will continue to be voiced. A post-first year entry scheme, in which law is taught to a large pool of potential applicants, merits serious consideration both for the intrinsic merit of such a course within a liberal education, and for its use as a basis of selection. The advantage that students will have some exposure to the academic study of law before applying to do a law degree, and therefore may be able to make a more informed choice than at present, would be an additional strength of such a scheme.

* Sydney University Law School.

** Department of Social Science \& Policy, University of NSW. This research was made possible by the generous financial support of the Law Foundation of NSW.

(C) 1992 (1992) 3 Legal Educ Review 235.

1 See for example, C Power, F Robertson \& M Baker, Access to Higher Education: Participation, Equity and Policy (Canberra: CTEC, 1986); Commonwealth Department of Education, Selection for Higher Education. A Discussion of Issues and Possibilities (Canberra: Department of Education, 
1986); Advanced Education Council Working Party on Course-related Matters, Initiatives in Advanced Education to Increase Participation and Equity - a Discussion Paper (Canberra, 1986).

2 A number of interesting schemes are evaluated in R Toomey ed, Educational Equity and Tertiary Selection Procedures (Canberra: CTEC, 1987). See also, T Hore \& B Barwood, Strategies for Improving Access (1989) 32 Aust U Rev 2-5.

3 See, for example, the scheme in Victoria which has been running. since 1976. This is reviewed in M Batten, The STC Course as an Alternative Preparation for Tertiary Education (1989) 32 Aust U Rev 14-16.

4 For discussion of these issues, see Commonwealth Tertiary Education Commission, Australian Law Schools: A Discipline Assessment for the Commonwealth Tertiary Education Commission (Canberra: AGPS, 1987) (Pearce Report) vol 2, 470-499; National Conference on Legal Education in Australia Proceedings, Legal Education in Australia (Melbourne: Australian Law Council, 1978) vol 1, 22-106; J Bradsen \& J Farrington, Student Selection and Performance in the Faculty of Law, The University of Adelaide (1986) 1 Aust U Rev 25-31.

5 The Medical School at the University of Newcastle has developed an alternative basis for admission which requires a threshold ability academically, but which then selects from within that pool on the basis of psychological tests and interviews. The University of Newcastle, Faculty of Medicine, Selecting Medical Students - A Workshop - Summary of Proceedings (Newcastle: University of Newcastle, 1987).

6 WKB Hofstee, The Case for Compromise in Educational Selection and Grading, in SB Anderson and JS Helmick eds, On Educational Testing 109-127 (San Francisco: Jossey-Bass, 1983).

7 The Faculty of Law at the University of Sydney participates in university-wide schemes which offer special admissions schemes for students who have suffered educational disadvantage, for aboriginal students, and for mature students without the usual HSC qualifications.

8 Table of preferences as at 13.11.90. University of Sydney, 1991 Local Admissions Statistics (Sydney: University of Sydney, 1991).

9 D Beswick et al, Selective Admissions Under Pressure (Melbourne: Centre for the Study of Higher Education, University of Melbourne, 1984).

10 C Power \& F Robertson, Selection, Entry Requirements and Performance in Higher Education, (Adelaide: National Institute of Labour Studies, 1987).

11 TR Dunn, An Empirical Demonstration of Bias in HSC Examination Results (1982) 26 Aust J Educ 190-203.

12 LHT West, Differential Prediction of First Year University Performance for Students from Different Social Backgrounds (1985) 29 Aust J Educ 175-187.

13 Power \& Robertson, supra note 10, at 14-17.

14 R Adams, Sex Bias in the ASAT? (Hawthorn, Victoria: ACddER, 1984); R Adams, Sex and Background Factors: Effect on ASAT Scores (1985) 29 Aust $J$ Educ 221-230. See also DJ Daley, Standardisation by Bivariate Adjustment of Internal Assessments: Sex Bias and other Statistical Matters, (1985) 29 Aust J Educ 231-247.

15 G Masters \& D Beswick, The Construction of Tertiary Entry Scores: Principles and Issues (Melbourne: Centre for the Study of Higher Education, University of Melbourne, 1986) 58-59.

16 Id at 84 .

17 The question whether males and females may reason in different ways, and therefore whether certain forms of testing are gender biased is relevant to Law. See C Gilligan, In a Different Voice (Cambridge, Mass: Harvard UP, 1982) as explored further in C Menkel-Meadow, Portia in a Different Voice: Speculations on a Women's Lawyering Process (1985) 1 Berkely Womens LJ 
39-63. Our study however, indicated no difference in overall performance between males and females.

Masters \& Beswick supra note 15, at 113.

19 Some students may have taken a Legal Studies course at school, but these courses do not have the same aims as does tertiary study. Tertiary study in Law does not build upon the knowledge acquired in school in the same way as is true in the sciences. For further discussion of secondary school courses see M Le Brun \& E Clark, The Growth of Legal Education in Australian Secondary Schools: Implications for Tertiary and Secondary Legal Education (1989) 1 Legal Educ Rev 21 7-235.

20 For various technical reasons, it was not feasible in our study to test correlations between individual subjects and law results in order to confirm or challenge this assumption.

21 D Hester, Selection for Tertiary Study in Australia (Adelaide: ACUE, University of Adelaide, 1989).

22 Id.

23 See W Pye \& B Kennedy, A Report of the Effect on Selection into Undergraduate Courses of Proposed Structural, Assessment and Curriculum Changes in Secondary Schools (Melbourne: Victoria Conference of Principals of Colleges of Advanced Education, 1985).

Commonwealth Department of Education, supra note 1, at 10-12.

The change also coincided with the introduction of a combined degree programme. For the results of Adelaide Law School's admissions' research, see Bradsen \& Farrington, supra note 4.

The proposal was that the students should apply for admission to law after at least one year of study in another university faculty, and that selection should be based upon performance in first year subjects.

27 A Ziegert, Social Structure, Educational Attainment and Admission to Law School (1992) 3 Legal Educ Rev (this issue).

28 It should also be noted that within the Graduate Law contingent in 1983 or 1984, there were those who had done a first degree at the University in earlier years, mainly in the late 1970s and early 1980s, and for whom the University also had records, including an HSC score. However, these students (in Category 6 - see following) were excluded from the HSC correlations, so as to ensure that only a recent HSC result was utilised.

29 As Table 3 records, there were 330 In the study as a whole who had one or more law results, but only 278 were recorded as taking Legal Institutions In Table 2. Legal Institutions was a prerequisite to further legal study. The reason for the discrepancy in numbers is because for a certain number of students, no HSC score was recorded on the student record, even though the student concerned entered the University directly from the HSC. Excluding those who were admitted to Law on the basis of a first degree, 779 students in the sample had an EEC score out of a possible total of 966. Of the remainder, a few had interstate or other qualifications, and in the rest the HSC data was missing. The data appeared to be missing on a random basis and the missing data was not confined to any one entry category. Most of the missing data related to a group of students with sequential University identification numbers.

30 If a student took Legal Institutions, failed it and took a supplementary examination, the average performance recorded was the average of the initial examination and the supplementary result.

31 The group does include two students in category seven who enrolled in Combined Law with a previous degree.

32 It will be noted that the correlation is rather higher for the total than for either of the groups separately. The probable explanation for this is that examining the total cohort expands the range of HSC scores. The Law students are grouped 
within a narrow HSC band, and while the HSC band for non-law students is rather broader, nonetheless this is still a limited range. Examining the entire cohort allows a range of comparison from below 300 to 490, and shows an increased correlation.

33 The number who had a set of first year non-law results in this study was lower than all the number of combined law students since a number had unorthodox patterns in which the first year law subject, Legal Institutions, was combined with some second year subjects. The computer programme returned a missing value for such students, with respect to their first year "non-law" result.

34 Beswick et al, supra at 133,140.

35 Beswick et al, supra note 9 at 133; Power and Robertson supra note 10 at 6165.

36 Ziegert, supra note 27.

37 See further J Mack, University Entry, Scaling and Mathematics, A Discussion Paper (Sydney: University of Sydney, 1989).

38 The total was in fact 65, but one student had a 4 unit maths score and no HSC aggregate recorded, and for that reason is not included in the sample.

39 It should be noted that correlations based upon different groups of students are not strictly comparable.

40 For students in the four year "straight law" degree, the figure is 15 subjects including four extended courses.

41 Unfortunately, it was not possible to compare Legal Institutions with average performance in Law excluding Legal Institutions.

42 Although it is typically employed with time series data, there is considerable evidence in econometrics literature that it can be a useful general purpose diagnostic tool in regression analysis.

43 Ziegert, supra note 27.

44 The majority of students in the Ziegert study who attended state or Catholic systemic schools were living in the more prosperous parts of Sydney. Id. 